\title{
Nanofiltration Technology for Toxic or Harmful Ions Removal from Groundwater: Characteristics and Economic Analysis
}

\author{
Xinzhu Yang', Xiaowei Wang ${ }^{2,3}$ \\ ${ }^{1}$ School of Mechatronic Engineering, Lanzhou Jiaotong University, Lanzhou, China; ${ }^{2}$ State Key Laboratory of Environmental Criteria \\ and Risk Assessment, Chinese Research Academy of Environmental Science, Beijing, China; ${ }^{3}$ State Key Laboratory of Water Envi- \\ ronment Simulation, School of Environment, Beijing Normal University, Beijing, China. \\ Email: vingo927@163.com, yangxinzhu@mail.lzjtu.cn
}

Received December $30^{\text {th }}, 2011$; revised January $29^{\text {th }}, 2012$; accepted February $28^{\text {th }}, 2012$

\begin{abstract}
Nanofiltration (NF) membrane can efficiently remove the ions from groundwater, especially for high valence ions. Results show that the removal rate of fluoride was approximately $67 \%$ by the NF system, while for arsenic the removal rate was more than $93 \%$. NF presented the well selective removal for fluoride. The quality of product water meets the national drinking water standards. Therefore, the application of nanofiltration technology can significantly improve the drinking water environment of rural areas, avoiding the secondary pollution caused by other chemical treatment processes. The water product cost of NF technology is about RMB 0.026 yuan per liter, application of the process of 2:1 NF membranes arrangement for toxic or harmful ions removal from groundwater, including investment cost and operating cost. Therefore, NF technology for harmful ions removal is more economical than the price of the market bottled water and suitable for application in rural areas of China.
\end{abstract}

Keywords: Nanofiltration; Economic Analysis; Toxic or Harmful Ions; Groundwater

\section{Introduction}

In rural China, the problem of the high toxic or harmful ions in groundwater is still widespread and serious, eg. high fluoride, arsenic, etc. [1,2]. The healthy drinking water requires removing the excess fluorid, but then the beneficial ions, e.g. $\mathrm{F}^{-}, \mathrm{Mg}^{2+}$, and $\mathrm{Ca}^{2+}$, etc., should be kept within appropriate concentrations.

Nanofiltration (NF) membrane process is a lower pressure needed and less pressure loss technology than Reverse Osmosis (RO), while it still has a higher rejecttion efficiency for (in)organic compounds than Ultrafiltration (UF) [3]. Especially, NF has the characteristic of selectively removing ions as the result of the combination effects of Donnan exclusion (membrane surface), steric-resistance or solution-diffusion [4,5], which means that some ions beneficial for human body are kept, as well as the fluoride, arsenic and other harmful ions are effectively removed [6-16].

China still lacks of the ability of large-scale production of NF membrane. However, NF membrane prices in market of the world have declined in recent years. Currently NF investment (considerable with reverse osmosis) is about RMB 600 yuan $\cdot \mathrm{m}^{-3} \cdot \mathrm{d}^{-1}$. The operating cost per $\mathrm{m}^{3}$ of water by NF technology depends on the raw water quality, membrane cleaning, water, electricity of pressure increase and the membrane service life, etc. The normal service life of NF can be 2 to 3 years, while UF is about 3 to 5 years [15].

Different arrangements of NF elements will result in absolutely diverse separation performances of NF systems, e.g., arrangement of NF elements in parallel can increase the product flux while arrangement in series can improve the water recover and minimize the concentrate flux, which are more concerned in actual application.

Usually, the water treatment processes application for the removal of harmful ions, face the problems of the aspects of environmental, economic and social effecttiveness. NF can effectively remove harmful ions of drinking water and therefore improve the drinking water environment of villages, and provide the protection of the residents health. NF process is the physical methods without adding other chemicals, which is the clean production technology. In this paper, 1) the feasibility analysis was conducted considering the performances of $\mathrm{NF}$ for removal of harmful ions from groundwater in rural areas; and 2) the economic benefit by NF technology was evaluated. 


\section{Materials and Methods}

\subsection{Materials}

NF negatively charged membrane elements were selected from GE Inc (USA), composing with three-tier structures: a three-dimensional surface with the cross-linked aromatic polyamide (PA) active layer, a polysulphone sublayer and a support layer (nonwoven polyester support structure). Table 1 shows the main properties of NF, with the desalination rates of $50 \% \sim 70 \%$ for $\mathrm{NaCl}$ and the molecular weight cut-off of $150 \sim 300$ dalton, which indicates the selective removal characteristic of NF.

The NF surface images (see Figure 1) with Environmental Scanning Electron Microscope (ESEM) demonstrate that the pores diameters of NF membrane are distributed within nano-meters.

Table 1. Parameters of NF membrane in the test [13].

\begin{tabular}{lc}
\hline Parameters $^{\mathrm{a}}$ & NF membrane \\
\hline Active area, $\mathrm{m}^{2}$ & 0.50 \\
Active layer material & Polyamide \\
Transmembrane Pressure $(\Delta P), \mathrm{MPa}$ & $0.35 \sim 1.6$ \\
Max operational temperature, ${ }^{\circ} \mathrm{C}$ & 90 \\
Molecular weight cut-off, dalton & $150 \sim 300$ \\
Desalination rates $(\mathrm{NaCl}), \%$ & $50 \sim 70$ \\
Requirement feed $\mathrm{pH}$ scope & $2 \sim 11$ \\
\hline
\end{tabular}

${ }^{\mathrm{a}}$ Reference from GE Water \& Process Technologies.

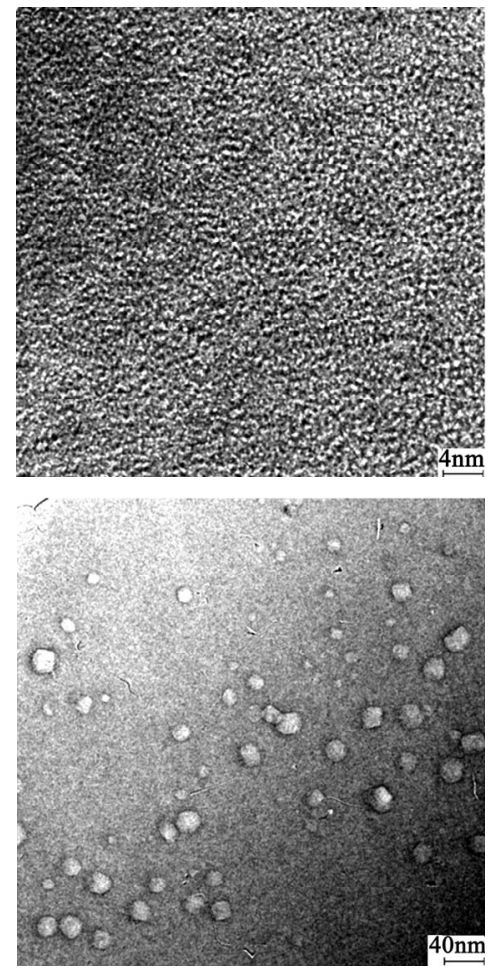

Figure 1. NF surface with Environmental scanning electron microscope (ESEM) (the scale bars are $4 \mathrm{~nm}$ and $40 \mathrm{~nm}$ respectively).

\subsection{Test Setup}

The feed tank with volume being $50 \mathrm{~L}$ contains a mixer to keep the solution concentrations of feed water proportional. Three prefilters in series are installed to remove the suspended particles $(0.5 \sim 100 \mu \mathrm{m})$. Product and concentrate waters are recycled to the feed tank in order to keep the concentrations of feed solutions stable, with equilibrium relationship $Q_{F}=Q_{C}+Q_{P}$ (see Figure 2).

Prior to use, membranes should be immersed in deionized water for 24 hours to ensure impurity being completely removed.

\subsection{Test Methods}

Raw groundwater was got from a $300 \mathrm{~m}$ depth well. After the tester running for 1 hour, the water samples were obtained from product and concentrated respectively (three parallel samples every $30 \mathrm{~min}$ ).

\subsection{Analytical Methods}

TDS/EC is assayed with TDS/EC meter (HANNA, HI99300); $\mathrm{pH}$ values were assayed with Sartorius (PB-21, Germany) $\mathrm{pH}$ meter; the anions are assayed with Ion Chromatography (ICS-2000, DIONEX, USA), and the cations are assayed with Atomic Absorption Spectrophotometer (TAS-990, Beijing Purkinje, China).

\subsection{Equations}

Water recovery rate $(Y)$ of NF membrane is calculated as in

$$
Y=Q_{P} / Q_{F} \times 100 \%
$$

while rejection rate $(R)$ of defluorination is calculated as in

$$
R=C_{P} / C_{F} \times 100 \%
$$

where $Q_{F}$ and $Q_{P}$ are the feed water flow and the product water flow $\left(\mathrm{L} \cdot \mathrm{h}^{-1}\right)$, respectively; $C_{F}$ is the feed water concentration and $\mathrm{CP}$ is the product water concentration $\left(\mathrm{mg} \cdot \mathrm{L}^{-1}\right)$.

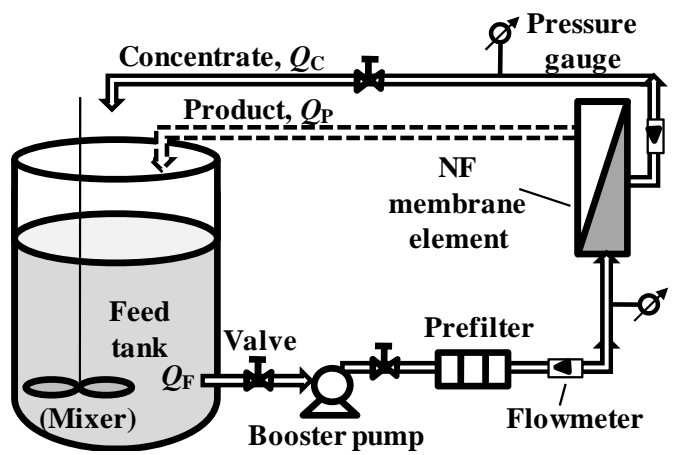

Figure 2. Test setup containing the NF membrane element. 


\section{Results and Discussion}

\subsection{Performances of Naofiltration for Ions Removal}

Figure 3 presents that, with NF membrane system, the rejection rates of bivalent ions are higher than that of monovalent ions, where the fluoride rejection rate is $67.3 \%$, and arsenic renoval is $93.4 \%$. The mechanism of this ions rejection sequence by NF are mainly ascribed to the effect of electric charge repulsion, usually called Donnan exclusion $[4,6]$. This explains that the potential difference, which is usually called Donnan potential, is generated at the interface between the NF membrane surface and ions to maintain electrochemical equilibrium. While multivalent ions especially of anions presents the stronger effect of electric charge repulsion than that of monovalent ions, and therefore the multivalent ions have the higher rejection rate during NF separation.

The ions rejection results show that NF has the excellent character of selective removal, which means that the potentially beneficial ions to human health can be retained, e.g. $\mathrm{Ca}^{2+}, \mathrm{Mg}^{2+}$ and $\mathrm{F}^{-}$. In addition, $\mathrm{F}$ - and As concentration in the product of NF membrane system can meet the national drinking water standard of China (GB5749-2006) in rural area $\left(1.0 \mathrm{mg} \cdot \mathrm{L}^{-1}\right.$ and $\left.0.01 \mathrm{mg} \cdot \mathrm{L}^{-1}\right)$.

\subsection{Economical Analysis of Naofiltration Technology}

In practice application, the process of the two NF membranes segment with parallel arrangement $(2: 1)$ was considered in order to obtain more water product and high water recovery rate $(Y)$. The process can produce about $37 \mathrm{~L} \cdot \mathrm{h}^{-1}$ water, and it can produce $296 \mathrm{~L}$ water with working for 8 hours per day. That can meet at least 10 to 15 family's water needs in daily life.

\subsubsection{Investment Cost}

The investment cost includes the NF membrane system equipment, automatic control systems, pipe valves and other cost components.

The NF membrane of this test system is small integrated water purifier for fluoride and arsenic removal, therefore the housing construction and labor maintenance costs is not considered. Currently, the market price of nanofiltration membrane (GE) is about 300 yuan (RMB) per $\mathrm{m}^{2}$, three membranes (GE-HL 1812) about 450 yuan, plus the cost of the membrane shell, a total of about 500 yuan. Cost of pipeline pressure booster pump is about 600 yuan, and two security filter costs about 10 yuan. The micro-controlled system costs 50 yuan. Besides, the cost of raw water pretreatment facilities includes pre-oxidation of trivalent arsenic in some type of aeration equipment and sodium ion exchange resin $(1.5 \mathrm{~kg})$ to soften cans (without consideration of other pretreatment facilities), is about 120 yuan. Pipes and valves cost 150 yuan. Therefore, the total investment cost is RMB 1380 yuan.

\subsubsection{Operating Cost}

Operating costs include electricity, equipment depreciation, loss of material, membrane cleaning fee, concentrated water treatment (central timing quantitative treatment) costs (without consideration of the management cost).

Electricity power consumption per hour is $0.55 \mathrm{~kW}$ (pipeline booster pump) $+0.22 \mathrm{~kW}$ (membrane pump) + $0.05 \mathrm{~kW}$ (trivalent arsenic pre-processing aeration) + electric energy loss, less than $1.25 \mathrm{~kW} \cdot \mathrm{h}^{-1}$. One $\mathrm{kW}$ electricity fee is 0.55 yuan, and therefore the electricity fee of the NF system is 0.688 yuan at most. 8 hours a day operation costs about 5.50 yuan. The main material depreciation cost including pump, shell, pretreatment tank, automatic control systems, pipes and valves, is about 900 yuan in total. If it can be used 3 years, the depreciation costs 0.82 yuan per day. The loss fees include loss of safety filter and nanofiltration membrane. Safety filter service life is about half a year, and then the two section

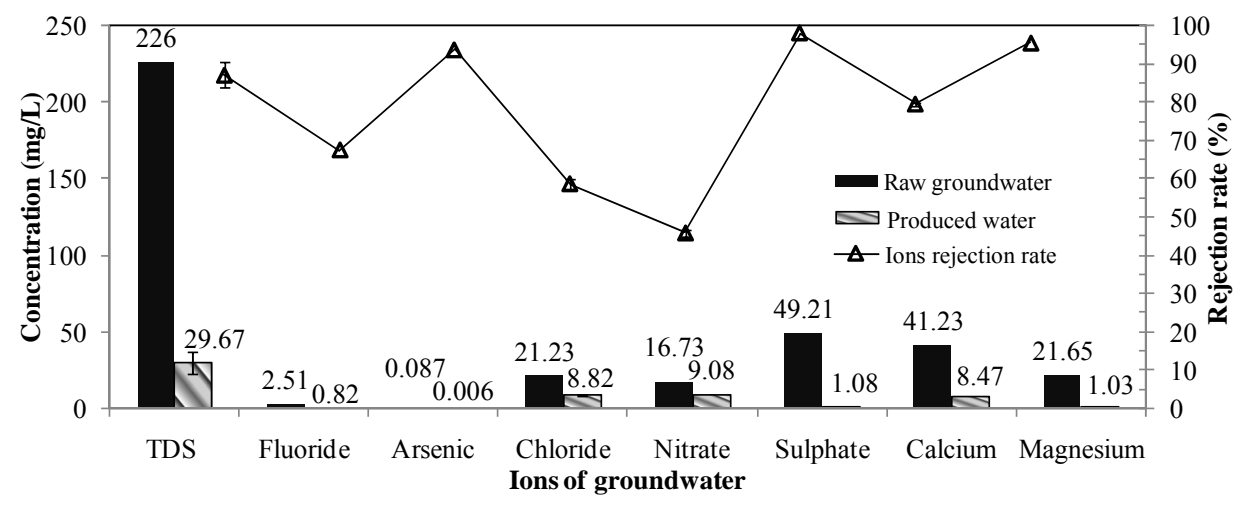

Figure 3. Performances of NF for toxic or harmful ions removal. Conditions: $\mathrm{pH}$ of 7.2, temperature of (16 $\pm \mathbf{0 . 5})^{\circ} \mathrm{C}$, $\mathrm{QF}$ of $(36 \pm 2) \mathrm{L} \cdot \mathrm{h}^{-1}, \mathrm{P}=(\mathbf{0 . 6 1} \pm \mathbf{0 . 0 1}) \mathrm{MPa}$, and $Y$ of $(30 \pm 3) \%$. 
safty filter loss fee is 0.056 yuan per day. Under normal circumstances, the NF membrane can be used for $2 \sim 3$ years, therefore the 3 membrane loss fee is 0.616 yuan per day. So the total loss cost was 0.7 yuan per day. After a period of operation, microfiltration and NF membrane need cleaning. Using $2 \%$ citric acid and ammonia $(\mathrm{pH} 3$ $\sim 4$ ) to acid chemical clean, they are washed once every three months. Cleaning cost is mainly due to the drug charges. Every cleaning cost is about 10 yuan, so the total cost was 0.11 yuan per day. Resin regeneration agent market price is 2 yuan per kilograms. With regeneration once every 3 days, each cost of the recycling agent is 0.2 yuan, and then the resin regeneration cost is 0.07 yuan per day. Concentrated water treatment fee is mainly due to the calcium pharmaceutical costs. Daily product flux is $296 \mathrm{~L}$ water every day, and membrane conversion rate is $64.9 \%$. Therefore the concentrated water output is $143.67 \mathrm{~L}$. Concentrated water treatment costs by 0.5 yuan. In all, the total operating costs is about 7.7 yuan per day.

\subsubsection{Water Product Cost}

The estimation of investment and operating cost presents that, the cost of water product with 296 liters is about 7.7 yuan, namely 0.0260 yuan per liter or 26 yuan per ton. As to commercially bottled water (including pure drinking water and mineral dinking water), considering the current minimum price of 8 yuan $\cdot$ barrel $^{-1}(18.9 \mathrm{~L} \cdot$ bar$\mathrm{rel}^{-1}$ ), every litre price is 0.423 yuan $\cdot \mathrm{L}^{-1}$, namely 423 yuan per ton. Therefore, the water product price is much lower than that of the market price of bottled water, application of the arrangement 2:1 NF membranes system to removal the high fluorine and arsenic.

\section{Conclusion}

NF presented the well selective removal for fluoride, and high rejection rates for arsenic. The quality of product water meets the national drinking water standards. Therefore, the application of nanofiltration technology can significantly improve the drinking water environment of rural areas. The water product cost of NF technology is about RMB 0.026 yuan per liter, application of the process of 2:1 NF membranes arrangement for toxic or harmful ions removal from groundwater. Application of NF technology can improve the quality of life for residents, improve the local investment environment and promote a new construction conditions in rural areas.

\section{Acknowledgements}

Many thanks are given to the Division of Drinking Water Safety Environmental Science \& Engineering of Tsinghua University for its technique and experimental support.
We thank for the help from the professor Desheng LI, who works at the School of Civil Engineering and Architecture, Beijing Jiaotong University.

Sincere thanks are expressed to the anonymous reviewers.

\section{REFERENCES}

[1] C. Zhu, G. Bai, X. Liu and Y. Li, "Screening High-Fluoride and High-Arsenic Drinking Waters and Surveying Endemic Fluorosis and Arsenism in Shanxi Province in Western China," Water Research, Vol. 40, No. 16, 2006, pp. 3015-3022. doi:10.1016/j.watres.2006.06.026

[2] M. L. Donacian, L. J. J. Antonius, S. Fernando, M. Robert and D. Pamela, "The Effect of Fluoride on Enamel and Dentin Formation in the Uremic Rat Incisor," Pediatric Nephrology, Vol. 23, No. 11, 2008, pp. 1973-1979. doi: 10.1007/s00467-008-0890-2

[3] Q. Wang, and W. Li, "Comparative Study on Fluoride Removal by NF and RO," Water \& Wastewater Engineering, Vol. 35, 2009, pp. 17-20. doi: CNKI:SUN:JZJS.0.2009-07-005

[4] A. Szymczyk, C. Labbez, P. Fievet, A. Vidonne, A. Foissy and J. Pagetti, "Contribution of Convection, Diffusion and Migration to Electrolyte Transport through Nanofiltration Membranes," Advances in Colloid and Interface Science, Vol. 103, No. 1, 2003, pp. 77-94. doi:10.1016/S0001-8686(02)00094-5

[5] A. Seidel, J. J. Waypa and M. Elimelech, "Role of Charge (Donnan) Exclusion in Removal of Arsenic from Water by a Negatively Charged Porous Nanofiltration Membrane," Environmental Engineering Science, Vol. 18, No. 2, 2001, pp. 105-113. doi:10.1089/10928750151132311

[6] S. Choi, Z. Yun, S. Hong, et al., "The Effect Ofco-Existing Ions and Surface Characteristics of Nanomambranes on the Removal of Nitrate and Fluoride," Desalination, Vol. 133, No. 1, 2001, pp. 53-64. doi:10.1016/S0011-9164(01)00082-0

[7] A. F. Reguillon, G. Lebuzit, D. Murat, J. Foos, C. Mansour and M. Draye, "Selective Removal of Dissolved Uranium in Drinking Water by Nanofiltration," Water Research, Vol. 42, No. 4-5, 2008, pp. 1160-1166. doi:10.1016/j.watres.2007.08.034

[8] C. K. Diawara, S. N. Diop, M. A. Diallo, M. Farcy and A. Deratani, "Performance of Nanofiltration (NF) and Low Pressure Reverse Osmosis (LPRO) Membranes in the Removal of Fluorine and Salinity from Brackish Drinking Water," Journal of Environmental Protection, Vol. 3, No. 12, 2011, pp. 912-917. doi: 10.4236/jwarp.2011.312101

[9] B. Van der Bruggen, K. Everaert, D. Wilms and C. Vandecasteele, "Application of Nanofiltration for Removal of Pesticides, Nitrate and Hardness From Groundwater: Rejection Properties and Economic Evaluation," Journal of Membrane Science, Vol. 193, No. 2, 2001, pp. 239-248. doi:10.1016/S0376-7388(01)00517-8

[10] K. Košutić, L. Furač, L. Sipos and B. Kunst, "Removal of Arsenic and Pesticides from Drinking Water by Nano- 
filtration Membranes," Separation and Purification Technology, Vol. 42, No. 2, 2005, pp. 137-144. doi:10.1016/j.seppur.2004.07.003

[11] C. Ratantamskul, K. Yamamoto and T. Urase, "Effect of Operating Conditions on Rejection of Anionic Pollutants In the Water Environment by Nanofiltration Especially in Very Low Pressure Range," Water Science Technology, Vol. 34, No. 9, 1996, pp. 149-156. doi:10.1016/S0273-1223(96)00798-6

[12] X. W. Wang, W. J. Liu, D. S. Li and W. F. Ma, "Arsenic (V) Removal from Groundwater by GE-HL Nanofiltration Membrane: Effects of Arsenic Concentration, $\mathrm{pH}$, and Co-Existing Ions," Frontiers of Environmental Science \& Engineering in China, Vol. 3, No. 4, 2009, pp. 428-433. doi:10.1007/s11783-009-0146-9

[13] X. W. Wang, B. D. Xi, S. H. Huo, W. J. Liu and D. S. Li, "Defluorination from Groundwater in Rural China by Nanofiltration Technology: Performance and Multistage
Arrangement," Environmental Pollution and Public Health Special Track within iCBBE2011, Wuhan, 10-12 May 2011, pp. 1-4. doi:10.1109/icbbe.2011.5780931

[14] G. T. Balleta, L. Gzaraa, A. Hafianea and M. Dhahbi, "Transport Coefficients and Cadmium Salt Rejection in Nanofiltration Membrane," Desalination, Vol. 167, No. 15, 2004, pp. 369-376. doi:10.1016/j.desal.2004.06.148

[15] X. W. Wang, B. D. Xi, S. H. Huo, W. J. Liu, D. S. Li, H. B. Yu, W. F. Ma and H. L. Liu, "Performances Comparison of Reverse Osmosis and Nanofiltration Application to Defluorination from Groundwater: Influence Factors and Fouling Analysis," Fresenius Environmental Bulletin, Vol. 20, No. 12, 2011, pp. 3141-3151.

[16] R. Rautenbach, K. Vossenkaul, T. Linn and T. Katz. "Waste Water Treatment by Membrane Processes-New Development in Ultrafiltration, Nanofiltration and Reverse Osmosis," Desalination, Vol. 108, No. 1-3, 1997, pp. 247-253. doi:10.1016/S0011-9164(97)00032-5 